\title{
Discussion on Curriculum Reform of Digital Image Processing under the Certification of Engineering Education
}

\author{
Jian Dong \\ School of Information Engineering, Yancheng Teachers University, Yancheng, China \\ Email: yctcdj@126.com
}

How to cite this paper: Dong, J. (2022). Discussion on Curriculum Reform of Digital Image Processing under the Certification of Engineering Education. Open Journal of Social Sciences, 10, 147-154.

https://doi.org/10.4236/jss.2022.101012

Received: December 17, 2021

Accepted: January 14, 2022

Published: January 17, 2022

Copyright $\odot 2022$ by author(s) and Scientific Research Publishing Inc. This work is licensed under the Creative Commons Attribution International License (CC BY 4.0).

http://creativecommons.org/licenses/by/4.0/

\begin{abstract}
At present, engineering education professional certification is being recognized by more and more colleges and universities. Engineering education professional certification is oriented by ability training, and puts forward specific reform requirements for all aspects of the talent training system. This paper takes the digital image processing course as an example and discusses the teaching reform under the talent training system of engineering education professional certification talents. In this paper, from the formulation of digital image processing curriculum objectives, the setting of teaching content, procedural assessment method, the design of online hybrid teaching mode, etc., and the three core concepts of engineering education professional certification to the application of the digital image processing teaching reform, practice has proved that after a series of teaching reform, the teaching effect has been greatly improved.
\end{abstract}

\section{Keywords}

Engineering Professional Education, Digital Image Processing, Teaching Reform, Online and Offline Mixed Teaching

\section{Introduction}

At present, engineering education professional certification has been recognized by more and more colleges and universities. The certification of engineering education is oriented by ability training, and puts forward specific reform requirements for the talent training system from seven aspects: students, training objectives, graduation requirements, continuous improvement, curriculum system, teaching staff and support conditions (Cui, Zou, Wang, Tang, \& Xia, 2020). 
More and more experts and scholars focus on education reform under the background of certification of engineering education. For example, $\mathrm{Xu}$ et al. proposed to build the "innovative" talent training system composed of the target concept system, the training implementation system, the training support system and the continuous improvement system (Xu, Zhao, Zhou, \& Li, 2020). Zhang et al. opined that it is necessary to make reform of traditional education mode and improve the carrier support and target acquisition taking the Outcomes-based Education (OBE) as guide, the innovation ability cultivation as objective, to provide effective guarantee for cultivation of the top-notch talents (Zhang, Ma, \& Song, 2017). In document, the author discussed the practical teaching system of computer science and technology based on output orientation (Wu, Fei, Yao, Zhu, \& Dong 2021), e.g. the reforms on the theoretical curriculum system, practical teaching system, innovation and entrepreneurship education system, and so on.

Generally speaking, the reform of the curriculum system is an important part of the reform of the talent training system. On the one hand, the reform of the curriculum system includes the innovation of the overall framework of the professional curriculum system, and on the other hand, the reform of the curriculum objectives, curriculum content, teaching mode and assessment mode of each course. This paper takes the digital image training course of digital media technology majors as an example to discuss the teaching reform under the certification talent training system of engineering education majors.

Digital image processing is a professional basic course in digital media technology in our school. This course takes "virtue" as the ideological and political line of the course (Zhang, 2021). To cultivate students' professional learning interest and love science, have the courage to explore, positive innovation, pragmatic scientific view and outlook on life, make students system to understand the basic concept of digital image, the principle of digital image formation, master the theoretical basis and technical methods of digital image processing, for the future can be engaged in the digital image processing research and technical method application work to master the necessary basic knowledge (The New Generation of Artificial Intelligence Development Plan, 2018). Since 2015, the State Council, the National Development and Reform Commission and the Ministry of Industry and Information Technology have issued the National Strategic Emerging Industries Development Plan during the 13th Five-Year Plan and the New-Year Artificial Intelligence Development Plan (Liu \& Zhang, 2020). The document puts forward higher and more urgent requirements for the training of information professionals, including digital media technology and its crossover fields. Digital image processing technology combined with ideological and political courses can help students establish the feelings and national pride that they love the motherland and their hometown. It can also combine the specific application of the corresponding application cases, so that students can clearly and intuitively grasp the basic ideas and implementation methods of the algorithm, stimulate students' interest in learning, and establish a positive 
learning attitude $(\mathrm{Hu}, 2020)$.

\section{Research Method}

This paper mainly uses three educational science research methods: literature research method, comparative research method and case analysis method.

Literature research method: by collecting, screening and summarizing works, papers, government documents and Internet materials related to the professional certification of engineering education, this paper combs the documents with historical value and reference value, and summarizes the experience and enlightenment that can be used for reference in the professional certification of higher engineering education on the basis of understanding, thinking and comparative analysis of previous research results, In order to support the construction of application-oriented talent training system in this paper.

Comparative research method: as for the professional certification of higher engineering education, foreign research is earlier. Studying the development trend of foreign engineering education certification is beneficial to promote the reform of Engineering Education in China, integrate its advanced ideas and implementation points into the process of applied talent training, and provide a new way of thinking for the construction of Applied Talent Training System in China.

Case analysis method: Based on the analysis of the certification concept of engineering education specialty, this paper selects the digital image processing course of digital media technology specialty in our university as an example to provide a practical reference for the optimization of the training objectives and graduation requirements of applied talents.

\section{Analysis of the Problems in the Teaching Process of Digital Image Processing}

At present, there are many problems in the teaching of digital image processing. In this section, we focus on the following three issues.

\subsection{Involved in Many Basic Courses, Strong Practical}

Digital image processing involves the content of multiple basic courses. For example, when teaching image coding, the knowledge about source information entropy involves information theory; the histogram of the image involves the theory of statistics; image segmentation, image enhancement, and image registration involves theoretical knowledge of partial differential equation, optimization theory, and so on; image recovery, edge detection need filter theory, similar examples vary. Therefore, digital image processing technology is actually a large synthesis of various theories in many engineering fields.

In addition, considering the characteristics of large digital image data, digital image processing technology in the course can only rely on computer programming, so the characteristics of the course, also make the implementation of the algorithm is basically in accordance with the teacher's example code of gourd, 
limit the students' innovation. When engineering problems change, students often do not know how to analyze and solve problems, which is also caused by the lack of theoretical knowledge mastery that cannot be converted into practical ability.

\subsection{The Teaching Content Is Too Traditional and Not Deep Enough}

The teaching content of digital image processing technology mainly includes:

(1) Digital image processing foundation. For example, the basic concept of the digital image digitization, the basic concept of the digital image, the file format of the digital image, the histogram.

(2) The image transformation. Such as the Fourier transform of the image, the wavelet transform, the discrete cosine transform.

(3) Photographic enhancement. Such as image enhancement point operation, spatial domain smoothing, spatial domain sharpening, frequency domain enhancement, color enhancement technology.

(4) Image recovery. For example, the mathematical model of image degradation, unconstrained recovery, inverse filtering, and Wiener filter.

(5) Image encoding and compression. It includes Hoffman coding, arithmetic coding, Feno-Xianon coding, linear and non-nonlinear prediction algorithms.

(6) Image segmentation. Includes edge detection operator, edge tracking algorithm, area segmentation, area growth, division and merging method;

(7) Binary image processing and shape analysis. Mainly includes morphological theory and application, image texture description. On the one hand, these knowledge points are not very correlated, and even many parts of the teaching content is independent of each other, making it difficult for students to form an overall cognition of the course content. On the other hand, this teaching content is too boring and makes students lose interest in learning. These two reasons ultimately make it difficult for students to form a knowledge system of the learning content, and lack a deep understanding of the learning content of this course.

\subsection{Teaching Models and Teaching Methods Lack of Innovation}

At present, the teaching method of digital image processing technology is similar to most professional courses majoring in digital media technology, and it adopts the mode of teaching first and then on-computer practice. Although more and more attention is paid to the teaching links of the computer practice, the practice links are highly similar to each course. For example, before class, the teacher pays attention to check the students' preview, and then explain the computer tasks one by one according to the teaching content of the theory class, and detailed clarify the basic principles, basic steps, matters needing attention, submitted document requirements of the computer content and so on. Finally, students can carry out various operations according to the on-up task book, and they do not need to think in detail about the various details of the code implementation. Although to this extent, students can understand and become familiar with the 
execution steps and process of code, in fact, students lack deep thinking, the content of the teacher only stay in simple memory, and cannot form a deep understanding. This has great limitations to the cultivation of students' hands-on ability, logical thinking ability, innovation ability, and even to the ability to solve complex engineering problems.

\section{Teaching Reform Combined with the Concept of Engineering Education Professional Certification}

In view of the problems pointed out in the third part, we put forward a series of reform measures from the perspective of mutual education professional certification, curriculum objectives, teaching contents, assessment methods and teaching modes.

\subsection{The Concept of Engineering Education Professional Certification}

Engineering education major certification adheres to the three concepts of "student-centered", "output-oriented" and "continuous improvement" as the core.

Student-centered does not mean that teaching activities are dominated by student will; no longer by a part of excellent students. Instead, the teaching objectives, teaching content, teaching mode, assessment methods and so on are centered around the students "ability training, so that the students can become the main body of teaching activities, so that the students" brain turn up, "learn" up, instead of blindly "listening" to the teacher under the traditional teaching concept.

Traditional teaching is curriculum course oriented, teachers can finish class, and students can complete the assessment (Zeng, 2021). And the output orientation means that all the teaching activities of the course must play a role in cultivating the students' ability. In the face of the demand of talent ability, all parties of the society and the market determine the positioning of the school. The positioning of the school determines the training goal of the major, and then determines the graduation requirements, curriculum system, curriculum objectives, the design of teaching activities and so on. At the same time, the market should make evaluation feedback on talents, and students should make evaluation feedback on the talent training program, so as to make timely improvement.

Teaching activities need to be evaluated with continuous improvement according to the actual situation, such as students' learning situation, the achievement of the last students and so on (Zhang, Wu, Shen, \& Shen, 2020). This requires us to develop a normal evaluation mechanism, and the purpose of the evaluation is to improve. In the traditional teaching activities, the teachers' improvement of the teaching activities is more based on their own subjective judgment.

\subsection{The Teaching Reform Practice of Digital Image Technology}

1) Program objective 
The training objectives of this major are: the all-round development of morality, intelligence, body, beauty and labor, With solid basic knowledge, basic skills and technological innovation ability in digital media technology related fields, With a sound personality, ideals and beliefs, social responsibility and international vision, Ability to adapt to the future career and social development, Can be in software companies, audio and video entertainment product development and production companies, game animation companies, advertising production companies, web portal sites and other IT related fields, Engaged in digital media development, multimedia design and production, game design and development, computer art design, computer animation design and production, Web design and website maintenance, information services, and digital media management, They can also be apply-oriented senior specialized personnel engaged in computer maintenance, software design, development and teaching in various administrative organs and public institutions.

2) Content of courses

Combined with basic requirements of values establishment and people cultivation, digital media technology professional digital image processing course in China's first lunar rover "jade rabbit" as the prototype, to require students to design their own lunar rover visual system as the main line will image preprocessing, image feature detection, image segmentation, image registration, image compression coding, artificial intelligence and other content runs together. First, students can have a holistic and systematic understanding of various image processing algorithms in the process of learning digital image processing technology, For example, what are the advantages and disadvantages of how various algorithms are algorithms, And can be according to the actual working environment of the rover to be various programs analysis, compare and comprehensive; next, The various basic algorithms taught in the course do not meet the actual requirements, Students are required to be able to seek alternative algorithms by consulting the relevant literature, Or that the algorithms are known to make appropriate improvements; once more, The parts of the rover visual system do not work independently, Students need to consider the mutual coordination between the various components of the system, Build a reliable lunar rover vision system; last, Through the rover vision system can expose students to current cutting-edge image processing technologies, Stimulate students' interest in learning science and technology and their patriotic feelings, Cultivate students to keep pace with The Times, have the courage to explore the scientific spirit, the learning spirit of hard study, Make the students have the scientific research concept of teamwork.

3) Evaluation mode

The assessment of digital image processing technology focuses on cultivating students' independent learning ability, project development ability and problem-solving ability, as well as unremitting exploration, pragmatic character and scientific view and teamwork spirit. The assessment method adopts: a) Process 
evaluation. Mainly includes classroom problem discussion, experimental report, online testing. The classroom problem discussion mainly discusses the common problems encountered by students in the design of the lunar rover system. The group students each take their own job to consult the information before class, and give their own plan according to the results of the research. During the discussion, all students discussed each group of plans; the teacher gave comments and scored. b) Final assessment. Students demonstrate and defend the respective complete lunar rover visual system in group form, and get the corresponding results. The final score of each student is: performance evaluation ${ }^{\star} 50 \%+$ final evaluation ${ }^{\star} 50 \%$.

4) Model of instruction

Since the epidemic, online teaching has become an important teaching means in daily teaching practice. The digital image processing technology course in this major has also accumulated rich online teaching experience during the epidemic. In general, we currently adopt online + offline hybrid teaching mode. Online teaching adopts the cloud class platform, and teachers release teaching videos online, mainly about the basic theories and basic methods of digital image processing, and throwing questions for students to think and discuss. In addition, do online tests when appropriate. Offline teaching mainly adopts the mode of flipped classroom, which requires students to analyze and describe the problems arising in the online teaching process, and give their own opinions for everyone to discuss. At the same time, teachers can make detailed explanations and comments on the difficulties and focus in the teaching content. Through the mode of online + offline teaching, students become the main body of teaching activities, and cultivate their ability to analyze complex engineering problems and solve complex engineering problems.

\section{Conclusion}

The course of digital image processing technology has achieved good teaching results through the reform of course objectives, course contents, assessment methods and teaching modes. For example, in the teaching of the last academic year, among the three curriculum objectives of this course, the achievement of Curriculum Objectives is good, mainly because the absolute value of each curriculum objective is high in the usual performance and final examination, which reflects that the students have a good learning attitude in the learning process, good attendance in class and examination, and have actively completed the learning tasks assigned by the teachers, Good results have also been achieved in the final examination, but the scoring results are not sufficiently differentiated. It should be considered to gradually increase the assessment differentiation in future courses to assess students' ability to solve complex engineering problems.

\section{Conflicts of Interest}

The author declares no conflicts of interest regarding the publication of this paper. 


\section{References}

Cui, W., Zou, J., Wang, F., Tang, T., \& Xia, P. (2020). Project-Driven Digital Image Processing Teaching Research under the OBE Concept. Atlas Journal, No. 6, 1031-1038.

$\mathrm{Hu}$, Z. (2020). Research Progress in Digital image Processing. China New Communications, No. 24, 72-73.

Liu, X., \& Zhang, M. (2020). Research on the Teaching Mode of the Integration of Online and Offline Mixing and Classroom Turnover: Taking the Strategic Management Course as an Example. Education and Teaching Forum, No. 51, 198-200.

The New Generation of Artificial Intelligence Development Plan (2018). Technology Guide, $36,113$.

Wu, C., Fei, F., Yao, E., Zhu, Y., \& Dong, W. (2021). Curriculum Reform of Sensor Theory to Cultivate Students' Ability of Solving Complex Engineering Problems for Engineering Education Professional Certification. China Modern Eduction Equipment, No. 21, 70-72.

Xu, D., Zhao, Y., Zhou, X., \& Li, N. (2020). Research on Innovative Personnel Training System of Measurement and Control Specialty under the Background of Engineering Education Professional Certification. Open Journal of Social Sciences, 8, 205-216. https://doi.org/10.4236/jss.2020.83018

Zeng, Q. (2021). Reform of Classroom Teaching Methods in Teacher Education Reflection and Reconstruction of Case Teaching to Traditional Classroom Teaching Methods. Teacher Education Forum, No. 34, 87-92.

Zhang, H. (2021). Discussion on the Ideological and Political Teaching of the Remote Sensing Digital Image Processing Course. Science, Education and Culture Hui (Next Ten Magazine), No. 10, 95-97.

Zhang, W., Ma, H., \& Song, X. (2017). Cultivation of Innovation Ability of Students in the Discipline of Food Science and Engineering from the Perspective of Engineering Professional Certification. Asian Agricultural Research, No. 2, 6.

Zhang, X., Wu, H., Shen, Z., \& Shen, D. (2020). On the Path of Innovation and Development of Teaching Supervision Work in Colleges and Universities Oriented by Continuous Improvement. Higher Agricultural Education, No. 6, 51-54. 